\title{
Comparative Analysis of Human Amniotic Membrane Graft versus Contact Lenses in Symptomatic Bullous Keratopathy
}

Venegas $\mathrm{L}^{1}$, Hettich $\mathbf{M}^{1}$, Villena $\mathrm{J}^{4}$, Aris $\mathbf{R}^{4}$, Párraga $\mathbf{M}^{4}$, Parolini $\mathbf{O}^{2}$, Alaminos $\mathbf{M}^{3}$, Campos $\mathrm{A}^{3}$ and $\mathrm{San}_{\mathbf{M}}$ Martin $\mathrm{S}^{4 *}$

${ }^{1}$ Ophthalmology Unit, Van Buren Hospital, Valparaiso, Chile

${ }^{2}$ Centro di Ricerca E. Menni, Fondazione Poliambulanza-Instituto Ospedaliero, Brescia, Italy

${ }^{3}$ Department of Histology, University of Granada, Spain

${ }^{4}$ Biomedical Research Centre, School of Medicine, Universidad de Valparaiso, Chile

\begin{abstract}
Bullous Keratopathy (BK) is a corneal disease involving the production of vesicles, chronic eye pain and visual acuity decrease. Definitive treatment is corneal transplant; however, donated corneas are not always available, and may require a long waiting time. The available palliative treatment is the use of contact lenses, however, this may be associated with corneal neovascularization, lens displacement or loss, infections and discomfort for the patient.
\end{abstract}

Amniotic membrane is a structure obtained from human placenta that has been used in ophthalmology and more recently in novel regenerative medicine approaches mainly for its anti-inflammatory and anti-fibrotic properties, amongst other biological properties.

This study compares the use of amniotic membrane grafts versus contact lenses in patients suffering from BK who are waiting for a corneal transplant.

A randomized clinical trial study was performed with patients with diagnosis of BK. Twenty patients were randomized into 2 groups: patients treated with amniotic membrane and treated with therapeutic contact lenses. Eye pain intensity (analog visual scale), visual acuity (Snellen test); bullae, corneal epithelial defects, corneal neovascularization and complications (biomicroscopy) were compared during 6 months.

In the amniotic membrane-treated group the ocular pain was significantly lower after 7 days $(p=0.005)$ and 30 days $(p=0.002)$ from the surgical procedure as compared to therapeutic contact lenses group, but it increased at day $180(p=0.042)$. No statistical differences were observed for the other parameters evaluated. Amniotic membrane is a safe and efficient alternative to the therapeutic contact lenses to short term relief of ocular pain in patients with BK.

Keywords: Cornea; Amniotic membrane; Contact lens; Bullous keratopathy

\section{Introduction}

Handling of patients with severe eye surface injuries has always been challenging in the field of ophthalmology. One of the most significant pathologies causing ocular severe injuries is Bullous Keratopathy (BK). This disorder is caused by a failure in corneal endothelial pump $\left(\mathrm{Na}^{+} /\right.$ $\mathrm{K}^{+}$/ATPase) characterized by chronic stromal edema, and it tends to evolve to the production of corneal vesicles and bullae due to the drainage of fluid to the anterior corneal layers as a consequence of intraocular pressure [1]. Most common causes of BK are intraocular surgical procedures including those related to cataract surgery [2]. This entity conforms the first cause for corneal transplant in the USA (from 26 to $50 \%)$ and the second in Europe [3-5].

Clinically, BK is characterized by chronic ocular pain, which is secondary to recurrent epithelial defects, ocular surface inflammation and visual sharpness decrease [1]. Definitive treatment for patients with $\mathrm{BK}$ with remaining visual potential is corneal transplant. However, donor grafts are not always available and corneal transplants often require long waiting times. For those reasons, medical and surgical palliative measures should be temporarily used to relieve ocular pain. Among others, the use of therapeutic contact lenses stands out as one of the best alternatives due to its contribution to the prevention of epithelial falling and ulceration, acting as a mechanical bandage [6-8]. However, these contact lenses do not improve visual sharpness or contribute to the resolution of the problem that caused the corneal edema. In addition, prolonged use of contact lenses may be associated with potential complications such as ocular disturbance, superficial neovascularization, inflammation and corneal infections, together with the economic expenses that patients have to deal with [6].

In 1940, De Roth [9] described for the first time the use of human amniotic membrane (AM) in ophthalmology, and since that date, multiple studies guaranteed its application as an efficient treatment for ocular surface diseases [10-12], including BK [13-19]. AM is a thin membrane covering the fetal side of the placenta, and it consists of an epithelial monolayer, an interposing acellular basement membrane and a stromal layer. Both the epithelial and stromal/mesenchymal layer are of fetal origin [20]. The therapeutic effects of the AM seen in the application of this membrane in the field of ophthalmology are attributable to different biological and structural properties of the $\mathrm{AM}$ and, amongst others, involves three basic synergistic actions on the ocular surface: 1) induction of growth and proliferation of new epithelia on the tissues (cornea and/or conjunctiva), 2) control of the

*Corresponding author: Dr. Sebastian San Martin, Faculty of Medicine, Universidad de Valparaiso, Hontaneda 2664, Ed. Bruno Gunther, 2do piso. Código Postal 92-V, Valparaiso-Chile, Tel: 219-464-5289; E-mail: sebastian.sanmartin@uv.cl

Received July 22, 2014; Accepted November 25, 2014; Published November 27,2014

Citation: Venegas L, Hettich M, Villena J, Aris R, Párraga M, et al. (2014) Comparative Analysis of Human Amniotic Membrane Graft versus Contact Lenses in Symptomatic Bullous Keratopathy. J Stem Cell Res Ther 4: 250 doi:10.4172/2157-7633.1000250

Copyright: (c) 2014 Venegas L, et al. This is an open-access article distributed under the terms of the Creative Commons Attribution License, which permits unrestricted use, distribution, and reproduction in any medium, provided the original author and source are credited. 
inflammation of the tissues under the implant and 3) inhibition of fibrosis and neovascularization of the corneal stroma [21]. For all these reasons AM might be an effective treatment to ameliorate disturbances generated by BK, even because no graft rejection was observed after transplantation of allogeneic amniotic membrane-cells and amniotic tissues [22-26].

In the present work, we describe the results of a randomized clinical trial in which the AM grafting technique was compared with the use of therapeutic contact lenses for the management of symptomatic BK in patients waiting for a corneal transplant at Carlos Van Buren Hospital from Valparaiso, Chile.

\section{Patients and Methods}

\section{Study design}

Randomized clinical trial.

\section{Patients}

The universe of this clinical trial are all patients with clinical diagnosis of symptomatic BK (corneal bullae, recurrent eye pain, foreign body sensation and photophobia), diagnosed at the Department of Ophthalmology Hospital Carlos Van Buren, Valparaiso, Chile, who were on the waiting list for corneal transplant from January 2008 to October 2011. Excluded patients were those with medical contraindication to undergo surgery with topical anesthesia, patients with severe systemic conditions and patients with corneal infections.

Twenty patients, corresponding to universe of patients during this period, were accepted to participate in this study and included in this clinical trial. All patients provided written consent to participate in this study, and the trial was approved by the Ethics Committee of the Faculty of Medicine, Universidad de Valparaiso ( No10/2011). The study was registered in ClinicalTrials.gov (NCT01926535). Patients were randomized on a simple random basis from a prefabricated list and divided into two groups: study group $(\mathrm{N}=10)$, including patients treated with $\mathrm{AM}$, and control group $(\mathrm{N}=10)$, including patients treated with contact lenses.

Clinical data and the variables considered for the study were: demography, etiology of BK, ocular pain (evaluated by using a visual analogue scale ranging from 0 to 10) and visual acuity (Snellen scale). By using a bio-microscope, we evaluated the presence of bullae and epithelial defects per quadrant, with fluorescein test (scale ranging from 0 to 4 ) and neovascularization. After treatment, the same biomicroscope was used to check through direct observation the presence of AM and complications (infection, wound dehiscence, etc.) through serial controls performed over a period of 6 months.

\section{Interventions}

Human AM was prepared and preserved in the Biomedical Research Centre using a method previously described by Lee and Tseng (1995). In the study group, AM grafts of $1.5 \mathrm{~cm} \times 1.5 \mathrm{~cm}$ were implanted in the affected eyes using topical anesthesia. Each graft was sutured to the bulbar conjunctive tissue using 10-0 nylon sutures and a reinforcement stitch was applied at the cornea (Figure 1). Therapeutic contact lenses were applied in all patients included in the control group and the lenses were replaced every two months according to the preestablished gold standard for this procedure.

Clinical follow-up examination was performed on days $1,7,30$, and then monthly until 6 months for both groups. Both groups were managed with topical gentamicin each 4 hours during the first week after surgery.

\section{Statistical analysis}

Data were analysed with Stata SE 12.0 sofware. Results corresponding to continuous variables were described by medians and interquartile range (IQR) and categorical medians were described by percentages and frequencies. Mann-Whitney statistical test was used to detect statistical differences between two continuous variables, and Fisher exact test was used for categorical variables. Association between quantitative variables was established by Kendal's tau correlation test. For all analysis, a value of $\mathrm{p}<0.05$ was considered statistically significant and all analyses were carried out double tailed.

\section{Results}

\section{Demographical data and etiology of BK}

In both groups, the median age of the patients was 68.5 years. Minimum age was 42 years and maximum age was 85 years; $50 \%$ of patients corresponded to males and 50\% corresponded to females. Affected eye was the right one in 9 cases (45\%) and the left one in 11 cases (55\%) (Table 1).

The most frequent etiology for BK was previous eye surgery $(75 \%$ of all patients). Cataracts and pars plana vitrectomy were the major procedures involved with a frequency of $60 \%$ and $15 \%$ respectively (Table 1).

\section{Ocular pain}

Basal ocular pain level was significantly higher in control and study groups before treatment with contact lenses or AM (9.5 median in both groups) (Table 2). After surgery, pain was significantly reduced in the AM group after 7 days of the implant $(p=0.005)$ and at day 30 $(p=0.002)$. However, pain was higher in the AM group after 180 days of the surgical procedure $(\mathrm{p}=0.042)$, although remarkably lower as compared to the pre-treatment situation (Table 3 ).

\section{Corneal neovascularization}

Corneal neovascularization remained constant with time in both groups, although a non-significant increasing trend was observed in the contact lenses group at day 180 . Despite the differences not being significantly different, it is noteworthy that patients treated with AM did not show corneal neovascularization (Table 3).

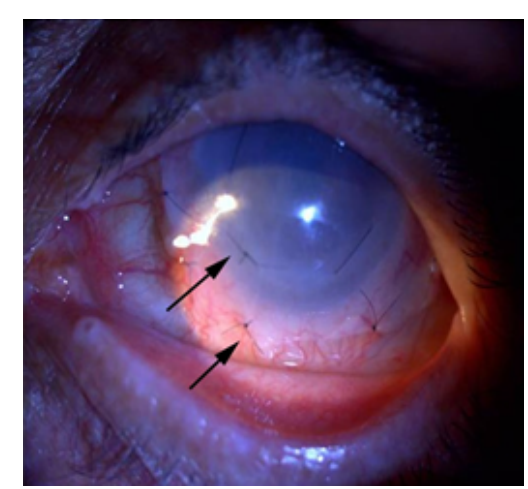

Figure 1: View of amniotic membrane graft sutured (arrows) to the bulbar conjunctive tissue and reinforcement stitch when applied at the cornea after one day of procedure. 
Citation: Venegas L, Hettich M, Villena J, Aris R, Párraga M, et al. (2014) Comparative Analysis of Human Amniotic Membrane Graft versus Contact Lenses in Symptomatic Bullous Keratopathy. J Stem Cell Res Ther 4: 250. doi:10.4172/2157-7633.1000250

Page 3 of 5

\begin{tabular}{|c|c|c|c|c|}
\hline \multirow{2}{*}{ Variables } & Total & Contact lenses & Amniotic Membrane & \multirow{2}{*}{$\mathbf{p}^{*}$} \\
\hline & n (\%) & $\mathrm{n}(\%)$ & n (\%) & \\
\hline Sex & \multirow{2}{*}{$10(50) / 10(50)$} & \multirow{2}{*}{$4(40) / 6(60)$} & \multirow{2}{*}{$6(60) / 4(60)$} & \multirow{2}{*}{0.37} \\
\hline Female/Male & & & & \\
\hline Affected Eye & \multirow{2}{*}{$9(45) / 11(55)$} & \multirow{2}{*}{$5(50) / 5(50)$} & \multirow{2}{*}{$4(40) / 6(60)$} & \multirow{2}{*}{0.5} \\
\hline Right/Left & & & & \\
\hline Etiology: & \multirow{2}{*}{$12(60)$} & \multirow{2}{*}{$7(70)$} & \multirow{2}{*}{$5(50)$} & \multirow{2}{*}{0.33} \\
\hline Pseudophakic & & & & \\
\hline Post Vitrectomy & $3(15)$ & $1(10)$ & $2(20)$ & 0.50 \\
\hline Post Trauma & $2(10)$ & $2(20)$ & 0 & 0.24 \\
\hline Corneal Dystrophy & $2(10)$ & 0 & $2(20)$ & 0.24 \\
\hline Toxic & $1(5)$ & 0 & $1(10)$ & 0.50 \\
\hline
\end{tabular}

Table 1: General characteristics of the patients included in the clinical trial. $\mathrm{P}$ values correspond to the statistical comparison of each variable between the control and the AM group. $n$ : Number of Patients; \%: Percentage of Patients.

\begin{tabular}{|c|c|c|c|c|}
\hline \multirow{2}{*}{ Variables } & Total & Contact Lenses & Amniotic membrane & \multirow{2}{*}{$p^{*}$} \\
\hline & m (IQR) & m (IQR) & m (IQR) & \\
\hline Pain & \multirow{2}{*}{$9.5(7.5-10)$} & \multirow{2}{*}{$9.5(7-10)$} & \multirow{2}{*}{$9.5(8-10)$} & \multirow{2}{*}{0.75} \\
\hline (visual analogue scale) & & & & \\
\hline Corneal neovascularization & \multirow{2}{*}{$0(0-2)$} & \multirow{2}{*}{$0.5(0-2)$} & \multirow{2}{*}{$0(0-2)$} & \multirow{2}{*}{0.97} \\
\hline (by quadrants) & & & & \\
\hline Bullae & \multirow{2}{*}{$0(0-2)$} & \multirow{2}{*}{$0.5(0-2)$} & \multirow{2}{*}{$0(0-2)$} & \multirow{2}{*}{0.48} \\
\hline (by quadrants) & & & & \\
\hline Visual sharpness & \multirow{2}{*}{$0.0052(0.0052-0.014)$} & \multirow{2}{*}{$0.0052(0.0052-0.014)$} & \multirow{2}{*}{$0.0096(0.0033-0.014)$} & \multirow{2}{*}{0.84} \\
\hline (Snellen) & & & & \\
\hline
\end{tabular}

Table 2: Distribution of study variables in each group before inclusion of each patient in the clinical trial. P values correspond to the statistical comparison of each variable between the control and the AM group. m: Median; IQR: Interquartile Range.

\begin{tabular}{|c|c|c|c|c|}
\hline \multirow{2}{*}{ Variables } & Total & Contact Lenses & Amniotic membrane & \multirow{2}{*}{$\mathbf{p}^{*}$} \\
\hline & m (IQR) & m (IQR) & m (IQR) & \\
\hline \multicolumn{5}{|l|}{ Pain } \\
\hline $1^{\text {st }}$ day & $1(0-2)$ & $1(1-2)$ & $0.5(0-1)$ & 0.2 \\
\hline $7^{\text {th }}$ day & $0.5(0-1)$ & $1(1-2)$ & $0(0-0)$ & $0.005^{*}$ \\
\hline 30 days & $0(0-1)$ & $1(1-2)$ & $0(0-0)$ & $0.002^{*}$ \\
\hline 90 days & $2(1-2.5)$ & $1(1-2)$ & $2(1-3)$ & 0.17 \\
\hline 180 days & $2(1-5)$ & $1.5(1-2)$ & $5(4-6)$ & $0.042^{*}$ \\
\hline \multicolumn{5}{|c|}{ Neovascularization } \\
\hline $1^{\text {st }}$ day & $0(0-2)$ & $0.5(0-2)$ & $0(0-2)$ & 0.97 \\
\hline $7^{\text {th }}$ day & $0(0-2)$ & $0.5(0-2)$ & $0(0-2)$ & 0.97 \\
\hline 30 days & $0(0-2)$ & $0.5(0-2)$ & $0(0-2)$ & 0.97 \\
\hline 90 days & $0(0-2)$ & $0.5(0-2)$ & $0(0-2)$ & 0.97 \\
\hline 180 days & $1(0-2)$ & $1.5(0.5-2)$ & $0(0-2)$ & 0.58 \\
\hline \multicolumn{5}{|l|}{ Bullae } \\
\hline $1^{\text {st }}$ day & $1(0-1)$ & $0.5(0-1)$ & $1(0-1)$ & 0.96 \\
\hline $7^{\text {th }}$ day & $1(0-1)$ & $0.5(0-1)$ & $1(0-1)$ & 0.86 \\
\hline 30 days & $0(0-1)$ & $0.5(0-1)$ & $0(0-0)$ & 0.15 \\
\hline 90 days & $0(0-1)$ & $0.5(0-1)$ & $0(0-0)$ & 0.15 \\
\hline 180 days & $0(0-1)$ & $0(0-1)$ & $0(0-0)$ & 0.43 \\
\hline \multicolumn{5}{|c|}{ Visual Sharpness } \\
\hline $1^{\text {st }}$ day & $0.0052(0.0052-0.0096)$ & $0.0052(0.0052-0.014)$ & $0.0052(0.0033-0.0052)$ & 0.18 \\
\hline $7^{\text {th }}$ day & $0.0052(0.0052-0.0096)$ & $0.0052(0.0052-0.014)$ & $0.0052(0.0033-0.0052)$ & 0.18 \\
\hline 30 days & $0.0052(0.0052-0.014)$ & $0.0052(0.0052-0.014)$ & $0.0052(0.0052-0.014)$ & 0.84 \\
\hline 90 days & $0.0052(0.0052-0.014)$ & $0.0052(0.0052-0.014)$ & $0.0052(0.0052-0.014)$ & 0.84 \\
\hline 180 days & $0.0052(0.0052-0.014)$ & $0.0052(0.0052-0.014)$ & $0.0096(0.0033-0.014)$ & 0.84 \\
\hline
\end{tabular}

Table 3: Distribution of study variables in each group after the use of contact lenses (control group) or amniotic membrane grafting (AM group) for different follow-up periods. $\mathrm{P}$ values correspond to the statistical comparisons between the control and the AM group. m: Median; IQR: Interquartile Range.

\section{Corneal epithelial defects}

When the presence of epithelial defects and corneal bullae was analyzed, we found that these remained stable with time in the contact lens group, whereas the AM group showed a complete epithelial regrowth after day 30 of treatment. Differences between both groups were not statistically different $(\mathrm{p}=0.15)$ (Table 3$)$. 


\section{Visual sharpness}

All patients had a highly compromised visual sharpness (less than 0.1 ) (Table 2). This remained stable with time in both groups after the follow-up period, and no statistical differences were found between control and AM groups (Table 3).

\section{Complications}

Five patients $(25 \%)$ showed minor complications: 2 (20\%) of the patients included in the control group developed a mild keratitis and loosening of contact lens and $3(30 \%)$ patients in the AM group had bacterial conjunctivitis ( 2 cases) or a partial detachment of the membrane at day 30 ( 1 case).

We did not observe any deterioration of the ocular surface condition after transplantation of the AM.

\section{Discussion}

Considering that the definitive treatment for patients with BK having a visual potential is corneal transplant, and that organ donation requires long waiting times in countries like Chile, it is essential to search for palliative therapeutic approaches for patients on the waiting list for corneal transplant. Although contact lenses may be effective for symptomatic relief, its use might favor the development of corneal infections, and their manipulation is not easy and requires frequent replacement. Interestingly in recent years, several studies have shown that AM grafting is an effective method for the treatment of a wide range of ophthalmic pathologies, including BK [13-19] which is associated with visual sharpness impairment and intense chronic ocular pain [1].

$\mathrm{AM}$ is able to induce epithelial re-growth, adhesion and differentiation, as well as to promote inflammation control and lower fibrotic reaction once implanted in the host tissues [21]. Therefore, the aim of this study was to compare symptomatology and improvement of BK disorder in patients using contact lenses versus receiving an AM grafting. In the last group, the combination of biological and mechanical effects of grafted AM [27] is probably related to the relief and control of the most invalidating symptoms of patients with BK.

Even though the number of patients included in the study was low due to the low prevalence of $\mathrm{BK}$ in the population, the selected patients are representative of the global population of patients with BK. In fact, we observed that the patient's profile was in agreement with that described in the literature [1,2]: aged people with previous intraocular surgical procedures as the most frequent etiology.

The results of this study suggest that significant relief of the painful symptomatology may be obtained with the use of AM as compared to the use of therapeutic contact lens. Even though these effects tend to decrease with time, probably due to AM resorption between day 60 and day 120 after surgery. According with Gris et al. the reabsorption of the $\mathrm{AM}$ is a natural phenomenon observed between the third and the fifth week after transplantation [28].

It is remarkable that patients treated with $\mathrm{AM}$ referred a total absence of pain since the first week until the control performed at day 90 , when a slight raise in painful symptomatology was observed. Strikingly, this pain after treatment was lower than the one registered in the pre-surgical evaluation. All these results made us think that the long-term analgesic effects of AM could be improved by repeating the technique after 3 months or by performing a bi-layer or multi-layer graft.

Although only non-significant differences were found for the presence of epithelial defects/corneal bullae between both groups, it is important to remark that AM induced a total restoration of the corneal epithelial barrier from the first month after grafting and that it remained constant during the whole period of time evaluated. This is one of the most important factors for the defense against the development of potential corneal infectious complications such as bacterial ulcerae. On the other hand, none of the techniques were associated with de novo development of corneal capillaries, which could have compromised the optimal results of the future corneal transplant.

Another important factor to consider is the absence of statistically significant alterations of visual sharpness with the use of both techniques even though AM graft generated a mild decrease in visual sharpness just after surgery because the ocular surface was covered but was completely recovered once AM was resorbed.

In summary, we can confirm that the use of AM grafts is a surgical technique able to control epithelial integrity, preventing corneal invasion by conjunctival epithelia and maintaining the eye surface anatomy for future procedures on the cornea.

Although new clinical trials should confirm our results using a higher sample size, these suggest that the use of AM could represent a clinical alternative to the use of contact lenses in patients waiting for keratoplasty.

\section{Acnkowledgment}

This study was supported by the Biomedical Research Centre at Universidad de Valparaíso, Valparaíso, Chile; grant $n^{\circ} 05 / 2006$ and the National R+D+i 2004 2007, the Institute of Health Carlos III. The authors offer thanks to Alejandra Moller and Marlene Riegel for their technical assistance.

\section{References}

1. Nishida T (1997) Cornea: Fundamentasl of cornea and external disease. St. Louis, Mosby.

2. Courtright P, Lewallen S, Holland SP, Wendt TM (1995) Cornea decompensation after cataract surgery. An outbreak investigation in Asia. Ophthalmology 102: 1461-1465. [PubMed]

3. Canner JK, Javitt JC, McBean AM (1992) National outcomes of cataract extraction. III. Corneal edema and transplant following inpatient surgery. Arch Ophthalmol 110: 1137-1142. [PubMed]

4. Cosar CB, Sridhar MS, Cohen EJ, Held EL, Alvim Pde T, et al. (2002) Indications for penetrating keratoplasty and associated procedures, 1996-2000. Cornea 21: 148-151. [PubMed]

5. Maeno A, Naor J, Lee HM, Hunter WS, Rootman DS (2000) Three decades of corneal transplantation: indications and patient characteristics. Cornea 19 7-11. [PubMed]

6. Jablonski J, Szafran B, Cichowska M (1998) [Treatment of corneal complications after cataract surgery with soft contact lenses]. Klin Oczna 100: 151-153. [PubMed]

7. Leibowitz HM, Rosenthal P (1971) Hydrophilic contact lenses in corneal disease. II. Bullous keratopathy. Arch Ophthalmol 85: 283-285. [PubMed]

8. Smiddy WE, Hamburg TR, Kracher GP, Gottsch JD, Stark WJ (1990) Therapeutic contact lenses. Ophthalmology 97: 291-295. [PubMed]

9. De Roth A (1940) Plastic repair of conjunctival defects with fetal membrane Arch Ophtalmol 23: 522-525.

10. Kim JC, Tseng SC (1995) Transplantation of preserved human amniotic membrane for surface reconstruction in severely damaged rabbit corneas. Cornea 14: 473-484. [PubMed]

11. Kim JC, Tseng SC (1995) The effects on inhibition of corneal neovascularization after human amniotic membrane transplantation in severely damaged rabbit corneas. Korean J Ophthalmol 9: 32-46. [PubMed]

12. Sangwan VS, Burman S, Tejwani S, Mahesh SP, Murthy R (2007) Amniotic membrane transplantation: a review of current indications in the management of ophthalmic disorders. Indian J Ophthalmol 55: 251-260. [PubMed] 
Citation: Venegas L, Hettich M, Villena J, Aris R, Párraga M, et al. (2014) Comparative Analysis of Human Amniotic Membrane Graft versus Contact Lenses in Symptomatic Bullous Keratopathy. J Stem Cell Res Ther 4: 250. doi:10.4172/2157-7633.1000250

Page 5 of 5

13. Espana EM, Grueterich M, Sandoval H, Solomon A, Alfonso E, et al. (2003) Amniotic membrane transplantation for bullous keratopathy in eyes with poor visual potential. J Cataract Refract Surg 29: 279-284. [PubMed]

14. Georgiadis NS, Ziakas NG, Boboridis KG, Terzidou C, Mikropoulos DG (2008) Cryopreserved amniotic membrane transplantation for the management of symptomatic bullous keratopathy. Clin Experiment Ophthalmol 36: 130-135. [PubMed]

15. Lee HI, Ha SW, Kim JC (2006) A novel application of amniotic membrane in patients with bullous keratopathy. J Korean Med Sci 21: 324-328. [PubMed]

16. Lopez Ferrando N, Celis Sanchez J, Gonzalez Del Valle F, Lopez Mondejar E (2004) [Monolayered amniotic membrane transplantation as a palliative treatment for bullous keratopathy]. Arch Soc Esp Oftalmol 79: 27-31. [PubMed]

17. Mejia LF, Santamaria JP, Acosta C (2002) Symptomatic management of postoperative bullous keratopathy with nonpreserved human amniotic membrane. Cornea 21: 342-345. [PubMed]

18. Panda A, Pangtey MS, Sony P (2003) Response to symptomatic management of postoperative bullous keratopathy with nonpreserved human amniotic membrane. Cornea 22: 187-188. [PubMed]

19. Pires RT, Tseng SC, Prabhasawat $P$, Puangsricharern V, Maskin SL, et al. (1999) Amniotic membrane transplantation for symptomatic bullous keratopathy. Arch Ophthalmol 117: 1291-1297. [PubMed]

20. Parolini O, Alviano F, Bagnara GP, Bilic G, Buhring HJ, et al. (2008) Concise review: isolation and characterization of cells from human term placenta: outcome of the first international Workshop on Placenta Derived Stem Cells. Stem Cells 26: 300-311. [PubMed]
21. Shimmura S, Shimazaki J, Ohashi Y, Tsubota K (2001) Antiinflammatory effects of amniotic membrane transplantation in ocular surface disorders. Cornea 20: 408-413. [PubMed]

22. Akle CA, Adinolfi M, Welsh KI, Leibowitz S, McColl I (1981) Immunogenicity of human amniotic epithelial cells after transplantation into volunteers. Lancet 2 1003-1005. [PubMed]

23. Sakuragawa N, Yoshikawa H, Sasaki M (1992) Amniotic tissue transplantation clinical and biochemical evaluations for some lysosomal storage diseases. Brain Dev 14: 7-11. [PubMed]

24. Scaggiante B, Pineschi A, Sustersich M, Andolina M, Agosti E, et al. (1987) Successful therapy of Niemann-Pick disease by implantation of human amniotic membrane. Transplantation 44: 59-61. [PubMed]

25. Tylki-Szymanska A, Maciejko D, Kidawa M, Jablonska-Budaj U, Czartoryska B (1985) Amniotic tissue transplantation as a trial of treatment in some lysosomal storage diseases. J Inherit Metab Dis 8: 101-104. [PubMed]

26. Yeager AM, Singer HS, Buck JR, Matalon R, Brennan S, et al. (1985) A therapeutic trial of amniotic epithelial cell implantation in patients with lysosomal storage diseases. Am J Med Genet 22: 347-355. [PubMed]

27. Toda A, Okabe M, Yoshida T, Nikaido T (2007) The potential of amniotic membrane/amnion-derived cells for regeneration of various tissues. J Pharmacol Sci 105: 215-228. [PubMed]

28. Gris O, Guell JL, Lopez-Navidad A, Caballero F, Del Campo Z (1999) Application of the amniotic membrane in ocular surface pathology. Ann Transplant 4: 82 84. [PubMed] 